\title{
From Social Psychology to Cultural Psychology: The Redemption of Personality
}

\author{
Ferdinand Fellmann \\ Department of Philosophy, Chemnitz University of Technology, Chemnitz, Germany \\ Email: ferdinand.fellmann@phil.tu-chemnitz.de
}

How to cite this paper: Fellmann, F. (2017). From Social Psychology to Cultural Psychology: The Redemption of Personality. Psychology, 8, 1586-1600.

https://doi.org/10.4236/psych.2017.810105

Received: June 19, 2017

Accepted: August 22, 2017

Published: August 25, 2017

Copyright $\odot 2017$ by author and Scientific Research Publishing Inc. This work is licensed under the Creative Commons Attribution International License (CC BY 4.0).

http://creativecommons.org/licenses/by/4.0/

\section{(c) (i) Open Access}

\begin{abstract}
This paper is about the relation between personality and society regarding the contrast between Eastern and Western cultures. I first explain the psychological bases for individual differences in general. I then turn to Western individualism, especially in Germany. The historical roots of individualization are discussed in reference to philosophers of life and psychoanalysts. For these thinkers the focus is on sexual life as the pivot of personal identity. Ancestor worship, on the other hand, is the Chinese way (dao) to humanity (ren). Consequently, European individualism and egalitarianism on the level of globalization are found to be the mirror opposite of the call to hierarchy and harmony (hé) in Chinese communitarian society. In the outlook that follows, I propose a new synthesis of the two different patterns of culture. Cultural psychology, as I understand it, occupies an intermediate position between individual psychology and social psychology, saving personality from being nivellized by global consumerism.
\end{abstract}

\section{Keywords}

Personality, Individualization Theory, Sexual Life, Erotic Love, Cultural Psychology, Western Liberalism, Eastern Communitarianism, Social Harmony

\section{Introduction}

Personality represents a complex state which is in no way always experienced without complications. Since the beginning, philosophers and psychologists have thus been disturbed by the consciousness of self that involves a stream of thought, each part of which is experienced as "I" (James, 1950: pp. 291-401). In special situations people ask the existential question: "Who am I"? The person asking this question is not asking a mere trivial question that can be answered 
with information about biographical data, bodily, or characteristic traits. The "who" that is being asked about here refers to a mysterious fact, the one that we mean when we refer to a person as an irreplaceable being. We always do this but without ever really knowing what selfhood actually means. We are too familiar with our social environment to know what we are talking about.

The question of personal identity discussed here takes in account situations in which the individual is set apart from society as a creature whose being depends mainly on his self-awareness. In this situation people feel mentally homeless. This is the case in modern times when young people have experiences that their elders never had. As Mead (1970) wrote in her study of the generation gap, Culture and Commitment, children are facing a new area of skills, and can say to their parents that their experience is no longer of any great help for survival in what now is a brave new world. The process of cultural globalization has brought on a new set of conditions for participation and empathy. For the first time now, humans throughout the world, in their communication with one another, have become citizens of a global village that is held together by a shared knowledge and common democratic values. Modern humans are not only aware of living in different cultural circumstances, but actually feel that the very concept of culture has changed. In order fully to understand the underlying mechanism, it takes cultural psychology to solve the ontological problem of self-consciousness. The classical philosophy of the subject differentiates between an unchanging, substantial "I" and its changing representations, or accidents. But this model obviously does not do justice to self-experience which is always in connection with social environment, and faith, and culture. Because humans are not able to separate the changing cultural traits from personality, there will always be an ineradicable wish to social harmony.

Eastern communitarianism (not to be confused with outdated communist collectivism) in this paper is offset against the classical liberalism and egalitarian way of life in Western Europe, especially in Germany. The chief author to formulate this new way of seeing and living is the sociologist Ulrich Beck. In his important book The Risk Society he defines late modernity through the process of individualization (Beck, 1992). The core to individualization theory is the understanding that in Western societies there is no longer an individual who can properly be described as an identical person. Rather, "everyone is into something", and each person is said to be identifiable by reference to his own familiar context, his own mythology and foibles resulting in the "average exoticism of everyday life". The bestselling author Precht (2011) has made popular this idea of multiple identities in the vacuum of the self in his book Who am I and If So How Many.

\section{Horizons of the Construction of Personal Identity}

Personality as a problem is due to human nature, which is, unlike animals, not fixed; and it is often experienced by individuals as a kind of mental fluctuations. 
In order to fix personal identity, there must be a balance between being, wanting, and obeying, which all compete for the human's self-understanding. As classical individual psychology has shown the three categories create an area of conflict in which it is not always possible to achieve balance (Adler, 1925). According to Adler a personal self has to confront societal, love-related, and vocational forces. These stances determine the final nature of personality. This reminds one of the old, famous conflict between duty and inclination but also between inclinations that are mutually exclusive. This experience of difference, which can never be entirely done away with, makes answers to questions about the self considerably more difficult to find than those dealing with moral questions about what one ought to do, which seem simple in comparison. This experience brings about, above all, the "problematic natures" that cause the self to exist in a state of permanent uncertainty about who he really is. One must always be prepared to be surprised by oneself, and effort is required to avoid becoming the pathological case of a split personality (Laing, 1964).

The problem of personal identity is always latent in the individual. Conditions may arise causing the question to become urgent. The situational dependency of personal identity first comes to mind. In normal, everyday life things typically run as usual-external and internal stability are mutually dependent. Each person plays a role according to the expectations that society puts on him. But there are, of course, exceptional situations brought about by unforeseen occurrences, especially due to career failures or family separations. Folk psychology refers to these situations using the known and feared expression "things always seem to happen when you least expect them to". In any case, these situations occur more often than one would prefer. It is the moment when you feel as if the carpet is moving under you and you try to find solid ground to stand on. Personal identity is connected to the relative stability of intimate relationships with family and friends; and when this stability is lost individuals must strive to find a new way of living (Buss \& Hawley, 2011).

Another horizon of identity that extends beyond personal life is society. Classical sociology is dealing with common behavior patterns, whereas the aim of social psychology is to integrate subjective experience that makes society more flexible. The economic and political structures are fundamental, but equally important, or perhaps even more important, are the ideological frameworks, which always accompany these social factors. Here, the distinction between open and closed societies is crucial. In closed and traditional societies, the individual remains bound to collective behavior and fixed thinking patterns. In ancient Chinese society, family tradition and civil service played a central role, reflecting the strong influence of Confucian philosophy (Xu, 2006). The world of Confucius is a patriarchal construction of cultural psychology in which hierarchy and geometrical order dominate. In the Mandarin model of learning, there is respect for the ancestors, for the fathers, and for the women-mothers, wives, concubines, daughters-who all know and keep their place (Confucius, 1930). Only outsiders develop problems of personal identity. The main figure is Lao Tzu (Xu \& Yin, 
2006). His famous celebration of "the mysterious female" is in direct opposition to the dominant culture of civic duty. The Taoism of Lao Tzu held out a vision of culture to personality. But the flow of Tao went underground to surface only in isolated springs of Zen Buddhism.

In our century the opposition of Confucius and Lao Tzu is still at work in the backstage of Chinese culture. But with the opening of China to the West things will push traditional Chinese culture to keep progressing and refreshing To what end Chinese way of life will lead is difficult to predict (Schuman, 2015). Therefore it may be useful to have a look at the situation in open societies of the West like Germany. Here, the ways emancipated individuals organize their lives are, on the whole, a personal matter. "The End of Role Models" (Mitscherlich, 1992) is first apparent in the breakdown of the traditional family. Mother and father no longer act as obvious, recognized authorities for the child. This led to the "fatherless society", which can now be appended with "motherless society". Because a mother (if she is still having children) increasingly becomes her child's confidant, especially with her daughter with whom she talks about relationship problems. The transformation is subtle and is specific to particular social strata, but it cannot be overlooked: there is a developmental tendency in the direction of an egalitarian individualism, which creates new alternatives of identity for children in the same way as for adults. This tendency is also to be found in today's China where the traditional family unit is dissolving. Ordinary people are in search of spiritual nourishment they feel is missing in their private lives. Here Confucian thinking comes to the aid. It promises social harmony in a society where everyone fulfills their responsibilities without being deprived of personal development and creative freedom by global consumerism and well-being ideology.

\section{Identity and Individuality}

This sketch of the parameters of identity in modern times has shown that a workable concept of personality cannot be formed without a clarification of individuality. The concept of individuality being suggested here contains more than the differences that can be determined objectively. From an objective standpoint, the relation between identity and individuality is relatively easy to explain. Things such as persons can undoubtedly be identified by establishing their characteristics. This is used in the term "numerical identity", which Willard Van Orman Quine disguised in his famous statement: "no entity without identity" (Quine, 1960). Instead of “entity”, one could also say "individuality" whereby individuality is understood as the difference of characteristics. Even if two things have all of the same characteristics, one can still hold them apart by their spatio-temporal localization: because no one thing can be in two places at the same time, or, conversely, no two things can be in one place at the same time. In any case, to make an absolute spatio-temporal identification would require an all-knowing observer who can oversee all places at all times. Externally viewed, identity requires individuality in the sense of discriminability. Leibniz gets to the 
point exactly in his famous principle of the "identity of indiscernibles".

If one switches from objective to subjective experience, identity and individuality do not coincide. Aside from pathological cases, no one confuses oneself for another. That we can say "I" does not, however, require us to have knowledge of our characteristics or our life history. "Characteristics" are understood here not only as external traits but also as internal ones, thus, as that which is referred to as a "character's characteristics". Here the subjective standpoint is in no way superior to the view of the observer. The ignorance of one's own person does not change the fact that I experience myself as identical to me. We are dealing with self-sameness, which one always has as the experiencing subject. It forms the unavoidable reference point of personality.

But personal identity should not be understood as a timeless point or as a purely logical principle. Psychologically speaking, self-experience shows us an interesting fact: Even if we only know little about ourselves and in extreme cases nothing at all, we still feel ourselves as a person in a certain state. To this belongs the spatial localization as the "here", where we find ourselves, as well as the temporal localization of the "now" in which we are living. Even if one is able to reduce, for the most part, their perceived spatial position by closing his eyes to the purely tactile, the perceived temporal position still remains irreducible. Individual psychology, thus, gives internal sense primacy to external sense. Internal, temporal consciousness contains no data, but it does contain qualities, time and intensity. The states that have not yet become particular affects such as joy or sorrow must be articulated. One can speak of a kind of "life-feeling" that is bound to the body like the feeling of space and time. In the movable boundaries of our body we experience ourselves as different from others even if we are not making comparisons. It therefore does not remain with numerical agency; in self-experience we become aware of our individuality as something that is unique to our self-feeling. Numerical identity marks a gap that wants to be filled with subjective experiences. Intentional consciousness, or the "consciousness of something", is always at the same time consciousness of someone, namely, of oneself. This self is, however, not an object of knowledge but is, so to say, the "backside". With this the subject-object dualism of self-experience is overcome. Translated into psychoanalytical terms, this means that personality is a relation that springs from the latent unconscious to the manifest consciousness.

\section{Multiple Identities in a Runaway World}

The notion of a "runaway world" was introduced to social theory by Ulrich Beck. Beck's concern is that in modern Western societies individuals are left "to wander between functional worlds". For an increasingly egalitarian society the underlying principle is that people are required to organize a larger part of their own lives. This results in "elective biographies" for citizens and consequently the atomization of social relations which leaves individuals responsible for their own lives to an ever-larger degree. These new private connections in a variety of set- 
tings must be based on "altruistic individualism" rather than on any preexisting cultural sentiments and rules. The changes are nowadays most evident in the lives of emancipated women and in the proliferation of family models different from the nuclear model.

The pattern is familiar throughout Western societies. There is a reference to the psychological notion that each one of us is different from the other. Or, possibly, that everyone is different from how we perceive ourselves when safe behind our own front doors; different from what we might think of as "normal" even if that definition of normality merely refers to the way we choose to live our own lives. Rather than it being an objective observation that people are different, individual citizens should subjectively seek out their own individual differences as part of forging a personality. It may not be too far-fetched to suggest that among the only things which make us the same are the facts that we are expected to be subject to the same natural laws, that our common biology makes us react in broadly similar ways to governmental rules, and that the same problems of personal identity apply to us all.

The question is, therefore, in relation to equity, how can social norms account for these differences between us as individuals-or are there sufficient and adequate reasons for the law to treat us all as identical when we appear before the court? The answer to this question is not easily found. To begin with, it is useful to have a look at the cultural presuppositions of the process of individualization. Here cultural psychology has to be taken into account. Cultural psychology opens up the horizon of social psychology and is thus highlighting the relativistic side of social structures and norms. This opening up is not arbitrary but is based on the acknowledgement of human universals such as individual feelings of love and hate. In order to illustrate this point, German philosophers of life and psychoanalysts will be cited in detail: Arthur Schopenhauer, Sigmund Freud, and Heinz Kohut. The following presentation draws on my book: The Couple. Intimate Relations in a New Key (Fellmann, 2016). The passages have been modified to serve as components of cultural psychology rather than as instances of individual psychology. Already at this point it should not be concealed that in view of modern globalization these anthropological insights paradoxically contain the latent germ of post-modern degradation of personality.

\section{The Will to Live}

The German philosopher of life, Arthur Schopenhauer has created a new basis for the understanding of personal identity. For Schopenhauer personal identity does not result from the logical I as the highest point of knowledge, but from the elementary striving for self-preservation that penetrates every aspect of life. The prototype of self-preservation is, according to Schopenhauer, not hunger but love in its animalistic form of sexuality. That which gives consciousness coherence and unity must be something in humans that precedes their ideas and representations: 
"This, I say, is the will. It alone is unchangeable and absolutely identical, and has brought forth consciousness for its own ends. Therefore it is also the will which gives it unity and holds together all its ideas and thoughts, accompanying them like continuous harmony. Without it the intellect would no longer have the unity of consciousness, as a mirror in which now this and now that successively presents itself, or at the most only so much as a convex mirror whose rays unite in an imaginary point behind its surface" (Schopenhauer, 1966, Vol. II: p. 334).

Schopenhauer's concept of the will to live has nothing to do with freedom of choice, but represents a purely biological and psychological drive that spans all creatures. Because humans are driven by a will that is "blind", they feel themselves as one with all other creatures. This is the empirical content of Schopenhauer's metaphysics, which hypostatizes the will as the "essence" of nature or as the thing-in-itself. If one puts the metaphysical speculations on hold, the significant insight remains that the will to live is the emotional basis for personal identity:

"At bottom it is the will that is spoken of whenever 'I' appears in a judgment. Thus it is the true and final point of unity of consciousness, and the bond of all its functions and acts; it does not itself, however, belong to the intellect, but is only its root, source, and controller" (Schopenhauer, 1966, Vol. II: p. 334). For Schopenhauer, "this clinging to life can only be founded in the subject of it. But it is not founded in the intellect, it is no result of reflection, and in general is not a matter of choice; but this will to live is something that is taken for granted: it is a prius of the intellect itself. We ourselves are the will to live, and therefore we must live, well or ill" (Schopenhauer, 1966, Vol. II: p. 462).

Schopenhauer calls the intellect the servant of the will, not underestimating the well known master-slave dialectic. The will depends on knowledge, because if it were left to its own impulses, it would surely destroy itself. Intellect and will do not form a dualism as sensibility and thinking do in Kant's writings, but the intellect is an appearance of the will, its visible form. According to Schopenhauer, the will to live can never be broken but it can be governed and modified by a higher form of knowledge:

"For if the will to live is there, as it is the only metaphysical reality, or the thing-in-itself, no physical force can break it, but can only destroy its manifestation at this place and time. Thus the only way of salvation is, that the will shall manifest itself unrestrictedly, in order that in this individual manifestation it may come to apprehend its own nature. [...] Nature guides the will to the light, just because it is only in the light that it can work out its salvation. Therefore the aims of Nature are to be promoted in every way as soon as the will to live, which is its inner being, has determined itself" (Schopenhauer, 1966, Vol. I: p. 518).

Far-reaching conclusions can be drawn from this astounding turn of thinking for cultural psychology: Although the human experiences oneself as a self embedded in a particular social class, his identity points to a deeper layer of life that connects all humans. Schopenhauer does not trace personal identity back to ob- 
jective patterns of social behavior but to the participation in that which is common to all creatures: self-seeking. In other words, the will to live appears fully in every human personality.

But personal identity that is fueled by the will to live is solipsistic in nature. The human who experiences himself as the maximum of reality considers others to be mere phantoms. This idea changes by focusing specifically on sexuality. Because sexual desire is concentrated on the person one is in love with, the principle of individuation becomes the principle of reality. The presence of the other is not expressed in rational knowledge but in the pain and joy the lovers experience together. According to Schopenhauer, sympathy is the state in which this affinity is brought to self-consciousness. Schopenhauer's metaphysics of the will thus becomes more plausible for dealing with the social self connected to love as the intimate relationship between man and woman. Sexuality as a cultural force acquires a deeper meaning when seen through the lens of Eros (Fellmann \& Walsh, 2016). Eroticism thus opens the way for the derivation of individuality from sexual love-a way that connects Schopenhauer with the founder of psychoanalysis, Sigmund Freud.

\section{Sigmund Freud and the Construction of the Psychical Apparatus}

Sigmund Freud's concept of the libido is a translation of Schopenhauer's "will to live". Based on Schopenhauer's model, Freud reconstructs subjectivity as a "psychical apparatus" in which different authorities fight each other for supremacy: id, ego, and superego. Freud transfers these aspects of personality to the relation between the pleasure principle and the reality principle. The pleasure principle corresponds to the id: "No such purpose as that of keeping itself alive or of protecting itself from dangers by means of anxiety can be attributed to the id" (Freud, 1989: p. 198). Thus the "ego" as the controlling authority corresponds to what Schopenhauer called the "intellect" or "knowledge".

With his meta-psychological conception of the psyche as an apparatus, Freud struggles to get through the knots of the reflective theory of personal identity. In his functional description of the ego Freud is not bothered by the transcendental philosophical problem of unity. If one approaches Freud's description of the psyche from the perspectives of Kant or Fichte, and reads how Freud discusses the ego and the ego drives in an uncomplicated fashion, it feels like a relief. One immediately gets the impression that the past philosophical efforts to deal with the question of the unity of self-consciousness were driven by self-made logical and conceptual traps. Freud's discussion of the ego and how it is strengthened by the superego, or conscience, which acts as the mediator between the subject and the external world, is perceived by folk psychology as obvious, as straightforward.

Despite its immediate, obvious appearance, Freud's conception of the psyche as the balance between unconscious wishes and conscious norms is in any case troublesome. Freud gives humans the moral task of pushing through from the unconscious to consciousness, or from the id to the ego. But the primacy of the 
sexual drives that Freud himself observed does not allow the ego to reach, at any time, the status of an autonomous subject. For Freud the developmental history of the ego reflects the libido, which has a phylogenetic nature. Schopenhauer, who initially believed individuation was an illusion, had the presentment at the end of his life that individuality is more than an illusion and actually part of the human core. And even Freud said that the ego individuality goes deep into the "dark id", the core of human nature, where the drives are balanced. Freud reduces the conflicting relation between id and ego, on which the unity of self-consciousness is built, to the interaction of sexual impulses; and the survival of the individual depends on the success of this interaction. This can result in a dangerous division of the ego, which corresponds to the internal contradictoriness and turmoil of Schopenhauer's will to live. In this respect Freud never goes beyond Schopenhauer.

\section{From Infantile Sexuality to Self-Sublimation}

A further reason for his limited understanding of personal identity is also due to the fact that Freud used infantile sexuality as the model of ego development. The main features of Freud's sexual theory can be summarized in the following way: Sexuality makes its appearance in early childhood and proceeds through several stages. The first stage is the oral stage whereby the infant's lust for sucking the mother's breast becomes the aim, independent of the nourishment it provides "and for that reason may and should be described as sexual" (Freud, 1989: p. 206). The oral stage changes into the anal stage which ends in puberty with the emergence of the "phallic" stage. In this stage Freud describes girls as castrated boys because they had to be content with their clitoris as a penis substitute. Freud derives pathological characters from each stage: the manic-depressive is stuck in the oral stage; the obsessional neurotic is still in the anal stage; and the anxious neurotic is in the phallic stage. The male fear of castration corresponds to female hysteria - a disease that was invented by psychoanalysis.

Regardless of how it relates to the empirical diagnosis of individuals, it is undeniable that Freud in his development of the ego according to the model of infantile sexuality comes very close to a deterministic character formation. Of course Freud considers ego development in light of the "ego ideal" and "superego" as well as social factors, but these considerations are limited to modifications of the predetermined sequence of infantile sexuality, made up entirely of the pleasure principle. In view of this holistic state Freud considered the sexuality of adults, however, to be diminished due to the societal repression of drives and instincts. His sublimation theory is highly determined by European sexual morality. Against this background our detailed depiction of Freud's psychoanalytical view of consciousness is not an end in itself, but throws light on the cultural constitution of his time.

Throughout his life Freud was worried with the problem of cultural evolution. So he extended his psychoanalytic model of the psyche to serve as a means of understanding Judeo-Christian culture, as in Moses and Monotheism (Freud, 
1939). In his book Civilization and its Discontents (1930) he wrote that "there are certain difficulties in the very nature of culture which will not yield to any attempt at reform" (Freud, 1962: p. 62). The difficulties are the result of two antagonistic cultural forces: the life drive and the death drive, Eros and Thanatos. Nevertheless, regarding the future of society Freud showed a vain of tempered optimism. At the height of the economic disasters that had overtaken the West he ended the book with the famous words: "And now it may be expected that the other of the two "Heavenly Powers", eternal Eros, will make an effort to assert himself in the struggle with his equally immortal adversary" (Freud, 1962: p. 92).

The German-American philosopher and political theorist Marcuse (1955) took up these thoughts in his work Eros and Civilization: A Philosophical Inquiry into Freud. In contrast to Reich (1986) and Fromm (1994), called "neo-Freudian revisionists" because of their trend to harmonize psychoanalysis with philosophical idealism, Marcuse emphasized Freud's biological view of sexual development which he believed revealed individuality and personality as "secondary processes" and thus the "basic negativity in the foundation on which they rest" (Marcuse, 1955: p. 273). Marcuse wants to replace the negative anthropology of bourgeois society with a positive anthropology without giving up Freud's drive theory. He shares the view that the individual emerges from the limitations of early childhood sexuality; but unlike Freud, he believes that the pleasure principle even without the process of repressive sublimation is in the position to construct a good social life. This brought him to the idea of a culture beyond the reality principle that leads to a re-sexualization of the entire body, and therefore results in long-term social bonds. For Marcuse, the re-sexualization is, however, not the primitive release of sexual desires as Wilhelm Reich believed; instead it is the self-sublimation of sexuality in the medium of erotic fantasy-the dawn of a utopian pattern of future culture.

The concept of self-sublimation through fantasy runs into the danger of falling into a solipsistic aestheticism that eliminates real interpersonal relations. This danger can be escaped giving up Freud's orientation toward infantile sexuality and, instead, relying on the sexual partner orientation of adults. This is in no way a relapse into the one-dimensional personality concept of individualist psychology, but levels the way to an interpersonal theory of subjectivity, one which is not complete without the consideration of cultural identity. To experience oneself as an individual requires one to experience himself as being closely tied to the social world that one lives in, and at the same time as an independent person directed towards self-determination. Unlike the construct of the purely logical subject, the personal self is fed by the permanent conflict between individual and social needs, without which no one would be able to perceive himself as an autonomous personality.

\section{The Development of Self Psychology: Heinz Kohut}

Heinz Kohut, the American psychoanalyst originally from Vienna, best known for his development of self psychology ventured to ask how personal identity can 
be derived in the framework of psychoanalytic theory (Ellis \& Abrams, 2009). In contrast to traditional psychoanalysis, which focuses on drives (instinctual motivations of sex and aggression), internal conflicts, and dreams, self psychology placed a great deal of emphasis on the vicissitudes of social relationships. With his psychology of the self, Kohut endeavors to do nothing less than to create a synthesis between psychoanalytic empiricism - which Freud himself referred to as psychology "off one's own bat"-with social psychology. At first sight, Kohut seems to be bound to the individualist perspective, but on closer inspection culture comes into view. Kohut's restoration of the self follows mental practices analogous to the doctrines of traditional Chinese medicine with its aims of identifying patterns of disharmony and its methods of curing them (Xu, 2004).

This step beyond Freud lies in a new valuation of childhood subjectivity. The child searches for satisfaction not only in the acquisition of food but is driven by an emotional need for self-expression, which transcends its basic needs. Behind this is an energetic model of the organism, which Kohut clearly identifies. $\mathrm{He}$ begins with a "virtual self", the primary processes of which must be described "in terms of tension - of tension increase, of tension decrease-and not in terms of verbalizable fantasies" (Kohut, 2009: p. 101).

The idea of the virtual self, which Kohut also refers to as the core self, is driven by the need for self-expression, which makes the presence of another necessary, because he reacts to the expression of emotions. Kohut sees this constellation realized in the mother-child relationship. The mother is understood here as a sounding board for the child's expressions, she is the child's "self object", as Kohut expresses it in other parts of the text. The formation of the self-which ends in a circular argument in transcendental philosophical reflection theoryhas been shifted to the communication with the mother, who represents the child's wish projection. The culmination of Kohut's model is a pre-reflexive self that takes on a fictitious character. Through the representation of the mother, the child feels as if he is already an independent self. The child exhibits a "grandiose self" and the mother is for the child the "idealized imago"; the result of the interaction of the grandiose self and the idealized imago lead to the child's development into an adult personality.

\section{Maternal Love and Erotic Love}

Kohut by transforming Freud's psychoanalysis into psychology of the self has opened the way to social psychology. His theory of the self-object has, in contrast to the theory of individual self-reflection, the advantage that subjectivity can be derived from interpersonal relations. This approach protects against the idealistic hypostatization of the isolated subject. As we have seen, Kohut concentrates his view on the mother-child relationship. Of course, the parent-child relationship, especially the mother-child relationship is ontogenetically the primordial experience. But for the development of personal identity, adults depend on interaction with others. If someone surrenders himself entirely over to another-whether this is a person or an idea-he loses his identity and may show symptoms of schizoph- 
renia (Jing, 1995). The necessity of boundaries in no way cancels out an intimate relationship with another. The human is in need of an erotic bond to confirm his personal identity. But one must take into account that personality constituted by the male-female polarity is paradoxical. Each lover wants to internalize the other, or to "devour" the other, but no one wants to be devoured by the other. A permanent struggle therefore emerges, which Karl Jaspers referred to as "loving struggle" - a suitable term for the dialectical relation of nearness and distance (Jaspers, 1985: p. 125).

Kohut's psychology of the self integrates Freud's drive theory into a self-concept that prioritizes the interpersonal relations of subjectivity. In contrast to Freud who stressed the primary tie of the boy to the father Kohut concentrates, concerning intersubjectivity, on the mother-child relationship. This is, of course, is a step beyond Freud's patriarchal bias and corresponds to the ontogenetic perspective in which an asymmetrical relation between the mother and helpless child dominates. On the other side, adult sexual love has demands that are indispensable for the formation of an autonomous personality. Maternal love is not comparable to the love between man and woman, which always contains a moment of aggression and even a moment of hate. These moments suggest that that the constitution of the self is to be reconstructed according to the schema of Eros with its ambivalent attitude towards the beloved partner (Fellmann, 2016). In the erotic pair-relationship, the thesis here, personality is formed out of the dialectic of veiling and unveiling, which found its symbolic expression in the fig leaf of the biblical account of the fall of man.

Unfortunately, but historically compelling, the sexual orientation has its dangers. In the brave new world of consumerism sexuality has been reduced to sex as a good available at any time. As a result of the sexual revolution of 1968 people feel free in shaping individual personality but in reality they are victims of commercial interests. In the so-called fun-society personal identity has become "collective individuality", so to speak. Consequently, the redemption of personality is an urgent task for cultural psychology. This problematic state of affairs leads back to the fundamental question how individual differences between the sexes can be saved from economical and political instrumentalization. Erotic love is a worldwide phenomenon, and its primary function is to signal personal commitment and fidelity. Among the social circumstances that shape the individual character a long-term erotic bond appears to be the most important. How and why human pair bonding differs from animal "consortship" is explained by sociobiology (Wilson, 1975). When in chimpanzee troops an adult male and estrous female go off for copulation, this cannot be called privacy but the desire of not being disturbed. Only the intimate relation between a man and a woman can be considered to recognize the partner as an irreplaceable person. Originally in evolution, sex activity seems to have been anonymous, merely as giving relief to an insistent urgency. But as sexual life turned into long-term mating, a host of new emotions confronted the sexes. The close relationship with one beloved person can be felt as a relief or as a constraint. In the same way love 
may be a positive feeling, to be accepted and cared for, or a negative feeling, to be alone and isolated. Sex as the core of intimacy cannot be treated except in its social setting, and through its manifestations in other aspects of culture. We have reason to believe in accordance with cultural psychology that the dynamic provided by sexual orientation is the fundamental experience that has given rise to the development of human personality.

\section{Outlook: Personal Identity in the Global World}

Having discussed the meaning of intimate relations and communication in individualistic psychology, personality in the perspective of cultural psychology remains problematic. For the threefold relation between personality, society, and culture in our century globalization comes into play. Globalization is a world-wide phenomenon of social change. Academic literature commonly subdivides globalization into three major areas: economic globalization, political globalization, and cultural globalization. The cultural aspect of globalization includes the interchange of world views, ideas, and other aspects of culture. I am dealing with cultural globalization and the unique effects it has on the mental change of those involved. In my view, this is the most underrated aspect of globalization, much in need of being examined by cultural psychologists. Cultural psychology extends social psychology, but it always leads back to individual psychology, thus avoiding the pronounced relativism which tends to deny the universal nature of the human mind.

Cultural globalization is an ambivalent phenomenon with "credits and debits." To begin, let us consider the credit of globalization. It is obvious that the global interchange of world views helps to reduce stupid prejudices which guide and control social behavior of all kinds. People living in villages and small towns often feel controlled by their neighbors and tend to cultivate traditional hostilities. In the city, living together is more pragmatic because it is dominated by money. Thus, urbanization as an essential part of globalization brings about new ways of personal life. Historically, through globalization the ideas and values of European Enlightenment have become widespread all over the world, and globalization has helped to overcome the excesses of colonization. The Eurocentric view in particular that other races, and other cultures, namely the Chinese, are considered as inferior is no longer valid. Modern societies are showing a continuous increase of self-awareness that is considered to be the royal road to emotional and mental freedom.

The debit of globalization concerns the loss of being rooted in a familiar place. The need to feel at home with relatives seems an intrinsic part of human nature. This does not mean that people organize their ways of living together in the same fashion. On the contrary, human cultures show a wide range of strategies and practices over time, place, and family life. Despite these differences, intimacy is inherently value-laden; it reflects our needs, wants, priorities, and beliefs. We engage and organize our surroundings into the places and spaces that we call everything from home and community to homeland and state. Migrant workers 
are always longing for the green, green grass of home. Having to sleep in unfamiliar surroundings creates a mentality of living nowhere in particular, and makes personal freedom a psychological problem.

Credits and debits-which are weightier? I will give an ambiguous answer in view of cultural psychology. I consider globalization a process of broadening horizons, but, at the same time, it involves the dissolution of cultural identity rooted in a homeland. This ambivalence prevents my new synthesis from being either a clash of incompatible cultures or a final state of unified culture. It is, instead, an interaction of different positions, a cultural exchange that benefits both parties even in the very confrontation of their different life-styles regarding personality. In globalization, the demand for new forms of individual self-expression and self-validation is growing and legitimate. On the other hand, individualization has to be compatible with the tenets of social life according to the changing patterns of culture.

\section{Acknowledgements}

I would like to thank my colleague Horst Kruse for his help in the revision of this paper.

\section{References}

Adler, A. (1925). The Practice and Theory of Individual Psychology (Translated by P. Radin, Revised ed. 1929 \& Reprints). London: Routledge \& Kegan Paul.

Beck, U. (1992). Risk Society: Towards a New Modernity. London: Sage Publications.

Buss, D. M., \& Hawley, P. H. (2011). The Evolution of Personality and Individual Differences. New York, NY: OUP.

Confucius (1930). The Four Books. With English Translation and Notes by James Legge. Shanghai: The Chinese Book Company.

Ellis, A., \& Abrams, M. (2009). Personality Theories: Critical Perspectives. Los Angeles, CA: Sage Publications.

Fellmann, F. (2016). The Couple. Intimate Relations in a New Key. Wien: LIT.

Fellmann, F., \& Walsh, R. (2016). From Sexuality to Eroticism: The Making of the Human Mind. Advances in Anthropology, 6, 11-24. https://doi.org/10.4236/aa.2016.61002

Freud, S. (1939). Moses and Monotheism. Trans. K. Jones. New York, NY: Hogarth Press.

Freud, S. (1962). Civilization and Its Discontents. Trans, J. Strachey, New York, NY: W. W. Norton \& Company.

Freud, S. (1989). An Outline of Psycho-Analysis. Trans. J. Strachey, New York, NY: W.W. Norton \& Company.

Fromm, E. (1994). Escape from Freedom. New York, NY: Henry Holt and Company.

James, W. (1950). The Principles of Psychology (Vol. 1). New York, NY: Dover Publications.

Jaspers, K. (1985). Psychologie der Weltanschauungen. München: Piper.

Jing, W. (1995). Schizophrenia. Beijing: Chinese Medicine.

Kohut, H. (2009). The Restoration of the Self. Chicago, IL: UCP. 
https://doi.org/10.7208/chicago/9780226450155.001.0001

Laing, R. D. (1964). The Divided Self. An Existential Study in Sanity and Madness. London: Penguin Books.

Marcuse, E. (1955). Eros and Civilization. A Philosophical Enquiry into Freud. London: Routledge and Kegan Paul.

Mead, M. (1970). Culture and Commitment, a Study of the Generation Gap. New York, NY: Natural History Press.

Mitscherlich, A. (1992). Society without the Father. A Contribution to Social Psychology. New York, NY: Perennial.

Precht, R. D. (2011). Who Am I and If So How Many? London: Constable.

Quine, W. O. (1960). Word and Object. Cambridge, MA: MIT Press.

Reich, W. (1986). The Sexual Revolution. London: Farrar, Straus and Giroux.

Schopenhauer, A. (1966). The World as Will and Idea (Vol. I, II). New York, NY: Dover Publications.

Schuman, M. (2015). Confucius: And the World He Created. New York, NY: Basic Books.

Wilson, E. O. (1975). Sociobiology. The New Synthesis. Cambridge, MA: HUP.

Xu, Y. (2006). Confucius. A Philosopher for the Ages. Beijing: China Intercontinental Press.

Xu, Y., \& Yin, Y. (2006). Lao Tzu. The Eternal Tao TeChing. Beijing: China Intercontinental Press.

Zhang, Y. (2004). Zen and Psycholtherapy: View from a Chinese Psychologist. Victoria: Trafford Publishing.

Submit or recommend next manuscript to SCIRP and we will provide best service for you:

Accepting pre-submission inquiries through Email, Facebook, LinkedIn, Twitter, etc. A wide selection of journals (inclusive of 9 subjects, more than 200 journals)

Providing 24-hour high-quality service

User-friendly online submission system

Fair and swift peer-review system

Efficient typesetting and proofreading procedure

Display of the result of downloads and visits, as well as the number of cited articles

Maximum dissemination of your research work

Submit your manuscript at: http://papersubmission.scirp.org/

Or contact psych@scirp.org 